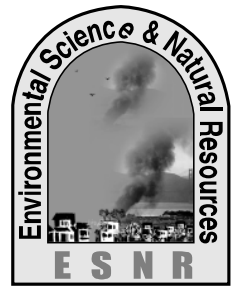

J. Environ. Sci. \& Natural Resources, 5(2): 119 -128, 2012

ISSN 1999-7361

\title{
Trend and Variability Analysis, and Forecasting of Maximum Temperature in Bangladesh
}

\author{
J. A. Syeda \\ Department of Statistics, Hajee Mohammad Danesh Science and Technology University \\ Dinajpur, Bangladesh
}

\begin{abstract}
An attempt is made to investigate the trend and variability for annual and seasonal (Three crop seasons) average maximum temperature (AMXT) for six divisional stations of Bangladesh: Dhaka, Rajshahi, Khulna, Barisal, Sylhet and Chittagong. The monthly AMXT (2009-2012) are forecasted applying univariate Box-Jenkin's ARIMA (autoregressive integrated moving average) modeling techniques. The growth rates of annual AMXT are found positive in all the stations except Rajshahi (negative) while the rates of their coefficient of variations (CVs) are negative in all the stations except Khulna (negative). The rates of AMXT are positive during Kharif season but negative in Prekharif and Rabi seasons for Rajshahi and Khulna, positive during Kharif and Rabi season but negative in Prekharif season for Dhaka and Barisal and positive in all the three seasons for Sylhet and Chittagong. The findings support that the climate of this country is channging in terms of maximum temperature and this may have adverse effects on its agriculture.
\end{abstract}

Key words: Forecasting Trend Analysis, Temperature

\section{Introduction}

Global warming is a challenging subject in climate research and it has observed that the global mean surface air temperature has risen by $0.6^{\circ} \mathrm{C}$ during the $20^{\text {th }}$ century and much of the increase has occurred in the last three decades. The plant growth and yield are highly dependent on temperature. Increased temperature can elevate the transpiration rate and reduce the moisture level for plant growth through decreasing rainfall. Crop yield may be reduced due to shortening of the growing period because of increased temperature. Excess temperature causes heat injury, retards growth, irreparable damage to cells and cytoplasm. Besides, there are other effects of excess temperature: killing of tissues, sunburn and sun scale in leaves and fruits too. Stem growth, quality, earliness or intensity of flowering and fruit development depend on temperature rhythms. Changes in temperature regime may retards plant growth and flowering (Lenka, 1998). In some cases flowers do not open fully or even fail to open. It also impairs formation and growth of fruit and maturity. Temperature change has direct impact on pests and diseases of plants. Many bacterial and fungal diseases reach at the severe level with the increase in temperature coupled with precipitation. The prediction of atmospheric parameters is essential for various applications like climate monitoring, drought detection, severe weather prediction, agriculture and production, planning in energy and industry, communication, pollution dispersal etc. But the weather prediction is a complex process and a challenging task for researchers. The accurate prediction of weather parameters is a difficult task due to the dynamic nature of atmosphere. So, for proper planning of expected crop yields, the study of the temporal maximum temperature and the forecasting of maximum temperature are much needed. In this paper, the within-year and between-year variability analyses are conducted for annual and seasonal AMXT and univariate Box-Jenkin's ARIMA (autoregressive integrated moving average) models are developed for monthly AMXT. In the within-year variability analyses, the maximum, mean and minimum AMXT and the coefficient of variation (CV) are used in detecting the pattern of AMXT variability in annual and seasonal aspects for a year. In the between-year variability analyses, the trend lines are estimated to investigate the year-to-year variation of different year/season for different stations.

\section{Sources of Data}

Methodology

Data are taken from Bangladesh Meteorological Department, Dhaka. The monthly AMXT in degree centigrade are taken for Dhaka, Rajshahi, Khulna, Barisal, Sylhet and Chittagong during 1953-2008, 1964-2008, 1948-2008, 1949-2008, 1956-2008 and 1949-2008, respectively. The missing data are filled in by the median of the corresponding years. The seasonal data for the three crop seasons: Kharif, Prekharif and Rabi are made by averaging the monthly data taken from June to October, March to May and November to February, in that order.

\section{Methodologies}

In this section, the multiple bar diagram for decadal average of Annual and Seasonal average maximum temperature (AMXT) has been constructed. The within and between-year variability for annual and seasonal AMXT are calculated. The linear trend for 
annual and seasonal AMXT are fitted with the least square method taking the following form of equation-

$$
\begin{gathered}
\mathrm{Y}=\mathrm{a}+\mathrm{bX} \\
\text { Where, } \mathrm{Y}=\mathrm{AMXT} \\
\mathrm{X}=\text { time } \\
\mathrm{a} \text { and } \mathrm{b}=\text { parameters }
\end{gathered}
$$

Stationarity of residuals for AMXT trend is tested using the ACF (autocorrelation function) and the PACF (partial autocorrelation function) display and the normality is checked by normal probability plot. The classical' $t$ ' value is used for the identification of significant AMXT trend when residuals follow the normality and stationarity pattern.

Univariate Box-Jenkin's ARIMA model is fitted to forecast the monthly AMXT data for January 2009December 2012. After confirming that the series is stationary, an effort is made for an ARIMA model to express each observation as a linear function of the previous value of the series (autoregressive parameter) and of the past error effect (moving average parameter). The available data are divided into training, validation and test sets. The training set is used to build the model, the validation set is used for parameter optimization and the test set is used to evaluate the model. The adequacy of the above model is checked by comparing the observed data with the forecasted results. The data for the last ten years are used to compare with the fitted model forecasts for the years and the models are selected for the minimum root mean square forecasting error of the data set of those ten years. The diagnostic techniques namely histogram of residuals, normal probability plot of residuals, ACF and PACF display of residuals, TS (time series) plots for residual versus fitted values and TS plots for residual versus order of the data are used for checking residuals of ARIMA models. Box-
Cox transformation is used for variance stabilization and the transformation of the data to get stationary series from nonstationary series (Pankraiz, 1991). The software package 'Minitab 13' is used to fit the ARIMA univariate models. A detailed description of the nonseasonal and seasonal ARIMA models and the standardized notation used is set in the Appendix 1.

\section{Box and Jenkins Modelling Strategy and ARIMA Model}

(Box and Jenkins, 1976) formalized the ARIMA modeling framework in the three steps: (I) Identification, (II) Estimation and (III) Verification. In the identification stage, it is tried to identify that how many terms to be included is based on the autocorrelation function (ACF) and partial autocorrelation function (PACF) of the differenced and/or transformed time series (Box and Jenkins, 1976). In the estimation stage, the coefficients of the model are estimated by the maximum likelihood method. The verification of the model is done through diagnostic checks of the residuals (histogram or normal probability plot of residuals, standardized residuals and ACF and PACF of the residuals). The performance of the ARIMA models is often tested through comparison of prediction with observation not used in the fitted model. An appropriate ARIMA model provides minimum mean squared error forecasts among all linear univariate models with fixed coefficients. It may produce point forecasts for each time period and interval forecasts constructing a confidence interval around each point forecast. To have the $95 \%$ interval for each forecast the formulae $f$ $\pm 2 s$ is used where $f$ denotes a forecast and $s$ is its standard error. The forecasts for a stationary model converge to the mean of the series and the speed of converging movement depends on the nature of the model. For nonstationary model the forecasts do not converge to the mean.

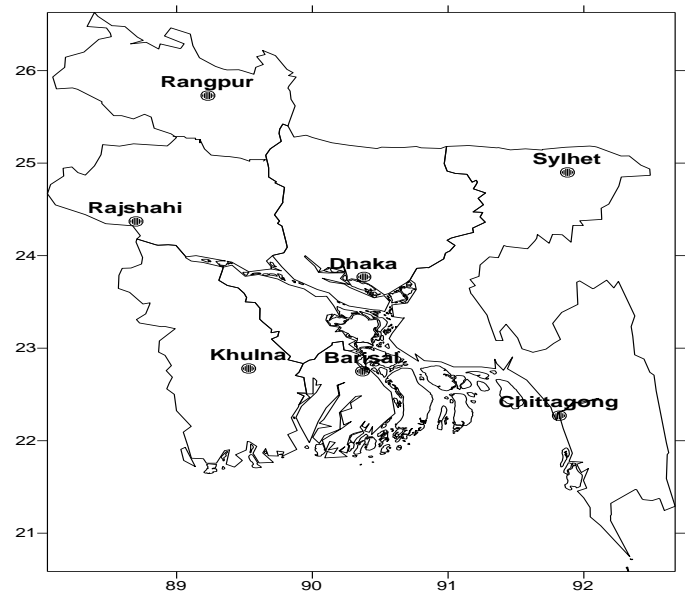

Fig. Divisional Map of Bangladesh. 


\section{Results and Discussions}

\section{Decadal Variability}

The decadal averages for annual and seasonal AMXT of six stations are presented in the Table 1. The data on AMXT of Dhaka is available for 1953-2008. The annual average AMXT increased from 33.33 during $1953-60$ to 33.40 in 1961-70 and reduced from 33.40 during $1961-70$ to 33.35 in $1971-80$ and again augmented from 33.35 during 1971-80 to 34.01 in 1981-90 and afterward went down from 34.01 during 1981-90 to 33.86 in 1991-00 and lastly elevated from 33.86 during $1991-00$ to 33.70 in 2001-08. The Kharif AMXT enhanced from 33.50 during 1953-60 to 34.96 in 1991-00 and dropped from 34.96 during 1991-00 to 34.85 in 2001-08. The Prekharif AMXT went down from 37.51 during 1953-60 to 36.48 in 1971-80 and expanded from 36.48 in 1971-80 to 36.95 in 1981-90 and fell from 36.95 in 1981-90 to 36.20 in 2001-08. The Rabi AMXT elevated from 29.99 during $1953-60$ to 30.78 in $1981-90$ and declined from 30.78 during $1981-90$ to 30.39 in 2001 08 .

The information on AMXT of Rajshahi is available for 1964-2008. The annual average AMXT dropped from 35.05 during $1964-70$ to 34.60 in 1981-90 and inflated from 34.60 during 1981-90 to 34.73 in 199100 and again fell from 34.73 during 1991-00 to 34.68 in 2001-08. The Kharif AMXT went down from 35.68 during $1964-70$ to 35.34 in $1981-90$ and boosted from 35.34 during 1981-90 to 35.79 in 200108. The Prekharif AMXT abridged from 40.35 during 1964-70 to 39.39 in 2001-08. The Rabi AMXT amplified from 30.28 during $1964-70$ to 30.42 in 1971-80 and diminished from 30.42 during 1971-80 to 29.96 in 1991-00 and again augmented from 29.96 during 1991-00 to 30.11 in 2001-08.

The statistics on AMXT of Khulna is available for 1948-2008. The decadal annual average AMXT developed from 33.71 during $1948-50$ to 34.60 in 1961-70 and abridged from 34.60 during 1961-70 to 34.13 in 1981-90 and again enlarged from 34.13 during 1981-90 to 34.46 in 2001-08. Similar pattern is observed for the decadal Rabi average AMXT. During Kharif season, the AMXT inflated from 34.01 during $1948-50$ to 35.12 in 1961-70 and diminished from 35.12 during $1961-70$ to 34.65 in $1971-80$ and again engorged from 34.65 during 1971-80 to 35.49 in 2001-08. During Prekharif season, the AMXT expanded from 36.11 during $1948-50$ to 38.03 in 1961-70 and dwindled from 38.03 during 1961-70 to 37.06 in 1991-00 and augmented from 37.06 during 1991-00 to 37.26 in 2001-08. During Rabi season, the
AMXT declined from 31.54 during $1948-50$ to 31.30 in 1951-60 and enhanced from 31.30 during 1951-60 to 31.38 in 1961-70 and again lessen from 31.38 during $1961-70$ to 30.77 in $1981-90$ and lastly developed from 30.77 during $1981-90$ to 31.08 in 2001-08.

The record on AMXT of Barisal is available for 19492008. The decadal annual average AMXT augmented from 33.38 during $1949-50$ to 33.45 in 1951-60 and decreased from 33.45 during 1951-60 to 33.18 in 1971-80 and again boosted from 33.18 during 197180 to 33.70 in 2001-08. The Kharif AMXT enhanced from 33.62 during $1949-50$ to 33.94 in 1971-80 and diminished from 33.94 during $1971-80$ to 34.56 in 1991-00 and again increased from 34.56 during 199100 to 34.55 in 2001-08. The Prekharif AMXT developed from 35.93 during $1949-50$ to 36.60 in 1951-60 and declined from 36.60 during 1951-60 to 35.70 in 1981-90 and again expanded from 35.70 during 1981-90 to 35.98 in 2001-08. The Rabi AMXT abridged from 31.15 during $1949-50$ to 30.12 in 1961-70 and went up from 30.12 during 1961-70 to 30.94 in 2001-08.

The fact on AMXT of Sylhet is available for 19562008. The decadal annual average AMXT of Sylhet reduced from 32.97 during 1956-60 to 32.77 in 197180 and amplified from 32.77 during 1971-80 to 34.08 in 2001-08. The Kharif AMXT dropped from 34.38 during $1956-60$ to 34.22 in 1971-80 and increased from 34.22 during $1971-80$ to 35.75 in 2001-08. The Prekharif AMXT went down from 35.81 during 195660 to 34.57 in 1971-80 and boosted from 34.91 during 1991-00 to 35.60 in 2001-08. The Rabi AMXT augmented from 29.09 during $1956-60$ to 30.84 in 2001-08.

The detail on AMXT of Chittagong is available for 1949-2008. The decadal annual average AMXT increased from 32.52 during $1949-50$ to 32.71 in 1951-60 and decreased from 32.71 during 1951-60 to 32.54 in 1961-70 and augmented from 32.54 during 1961-70 to 34.34 in 2001-08. The Kharif AMXT expanded from 33.21 during $1949-50$ to 33.56 in 1961-70 and dropped from 33.56 during 1961-70 to 33.47 in 1971-80 and again went up from 33.47 during 1971-80 to 34.78 in 2001-08. Prekharif AMXT enhanced from 34.40 during $1949-50$ to 34.55 in 1951-60 and declined from 34.55 during 1951-60 to 33.86 in 1981-90 and again expanded from 33.86 during 1981-90 to 36.43 in 2001-08. Rabi AMXT inflated from 30.25 during $1949-50$ to 30.35 in 195160 and went down from 30.35 during 1951-60 to 29.94 in 1961-70 and again boosted from 29.94 during $1961-70$ to 32.22 in 2001-08. 
Table 1. Decadal Averages of Annual and Seasonal AMXT for Six Stations

\begin{tabular}{|c|c|c|c|c|c|c|c|c|c|c|c|c|c|c|}
\hline \multirow{2}{*}{ Period } & \multicolumn{4}{|c|}{ Dhaka } & \multirow{2}{*}{ Period } & \multicolumn{4}{|c|}{ Rajshahi } & \multirow{2}{*}{ Period } & \multicolumn{4}{|c|}{ Khulna } \\
\hline & $\mathbf{A}$ & $\mathbf{K}$ & $\mathbf{P k}$ & $\mathbf{R}$ & & $\mathbf{A}$ & $\mathbf{K}$ & $\mathbf{P k}$ & $\mathbf{R}$ & & $\mathbf{A}$ & $\mathbf{K}$ & $\mathbf{P k}$ & $\mathbf{R}$ \\
\hline- & - & - & - & - & - & - & - & - & - & $1948-50$ & 33.71 & 34.01 & 36.11 & 31.54 \\
\hline 1953-60 & 33.33 & 33.50 & 37.51 & 29.99 & - & - & - & - & - & $1951-60$ & 34.29 & 34.72 & 37.58 & 31.30 \\
\hline 1961-70 & 3. & 3. & 3 & 31 & $1304-100$ & 30 & 3 & 40.35 & 30.28 & 1961-70 & 34.60 & 35.12 & 38.03 & 31.38 \\
\hline 1971-80 & 33.35 & 33.84 & 36.48 & 30.38 & 1971-80 & 34.85 & 35.43 & 39.79 & 30.42 & 1971-80 & 34.22 & 34.65 & 37.55 & 31.18 \\
\hline 1981-90 & 34.01 & 34.82 & 36.95 & 30.78 & $1981-90$ & 34.60 & 35.34 & 39.39 & 30.09 & $1981-90$ & 34.13 & 35.07 & 37.07 & 30.77 \\
\hline 1991-00 & 33.86 & 34.96 & 36.63 & 30.40 & 1991-00 & 34.73 & 35.61 & 39.62 & 29.96 & 1991-00 & 34.37 & 35.41 & 37.06 & 31.07 \\
\hline 2001-08 & 33.70 & 34.85 & 36.20 & 30.39 & 2001-08 & 34.68 & 35.79 & 38.95 & 30.11 & 2001-08 & 34.46 & 35.49 & 37.26 & 31.08 \\
\hline
\end{tabular}

Table 1. Continued

\begin{tabular}{|c|c|c|c|c|c|c|c|c|c|c|c|c|c|c|}
\hline \multirow[t]{2}{*}{ Period } & \multicolumn{4}{|c|}{ Barisal } & \multirow[t]{2}{*}{ Period } & \multicolumn{4}{|c|}{ Sylhet } & \multirow[t]{2}{*}{ Period } & \multicolumn{4}{|c|}{ Chittagong } \\
\hline & $\mathbf{A}$ & $\mathbf{K}$ & $\mathbf{P k}$ & $\mathbf{R}$ & & $\mathbf{A}$ & $\mathbf{K}$ & $\mathbf{P k}$ & $\mathbf{R}$ & & $\mathbf{A}$ & K & $\mathbf{P k}$ & $\mathbf{R}$ \\
\hline $1949-50$ & 33.38 & 33.62 & .93 & 31.15 & - & - & - & - & - & -50 & 32.52 & 33.21 & 34.40 & 30.25 \\
\hline $1951-60$ & 33.45 & 34.02 & 60 & 30 & $56-60$ & 32.97 & 34.38 & 5.81 & 29.09 & 60 & .71 & 49 & .55 & .35 \\
\hline 1961-70 & 33.19 & 34.00 & 35.94 & 30.12 & 1961-70 & 32.86 & 34.28 & 34.90 & 29.57 & 1961-70 & 32.54 & 33.56 & 34.33 & 29.94 \\
\hline 1971-80 & 33.18 & 33.94 & 35.58 & 30.44 & $1-80$ & 32.77 & 34.22 & 34.57 & 29.60 & 1971-80 & 32.59 & 33.47 & 34.03 & 30.40 \\
\hline $1981-90$ & 33.46 & 34.33 & 35.70 & 30.70 & $1981-90$ & 33.30 & 34.93 & 34.82 & 30.11 & -90 & 32.81 & 34.05 & 33.86 & 30.48 \\
\hline 1991-00 & 33.60 & 34.56 & 35.86 & 30.71 & 1991-00 & 33.60 & 35.44 & 34.91 & 30.31 & 1991-00 & 33.29 & 34.61 & 34.57 & 30.69 \\
\hline 2001-08 & 33.70 & 34.55 & 35.98 & 30.94 & 2001-08 & 34.08 & 35.75 & 35.60 & 30.84 & 2001-08 & 34.34 & 34.78 & 36.43 & 32.22 \\
\hline
\end{tabular}
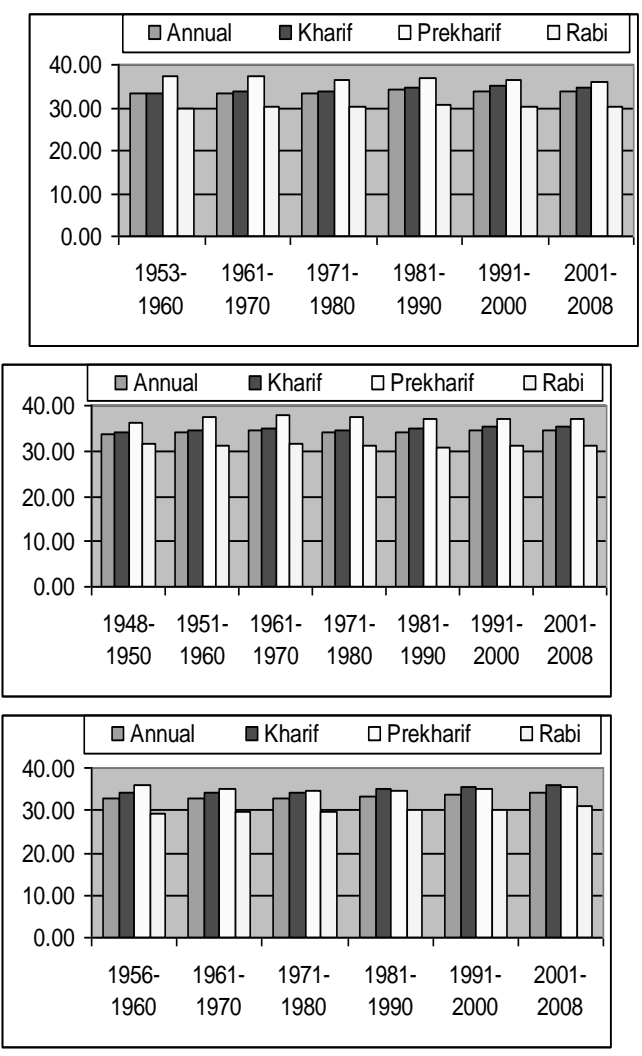
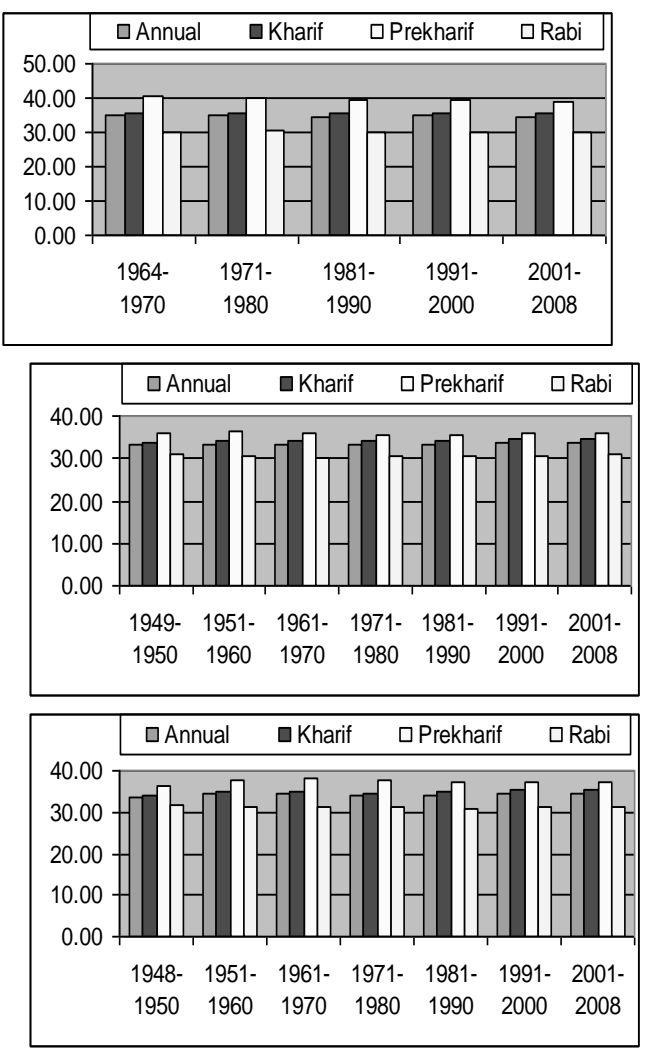

Fig.1. MBD for decadal average AMXT in (a) Dhaka (b) Rajshahi (c) Khulna (d) Barisal (e) Sylhet (f) Chittagong 


\section{Within-Year variability}

Table 2 presents the within-year variability for annual and seasonal AMXT for six divisions. The maximum, average and minimum AMXT are highest in Prekharif season nd lowest in Rabi season for all the stations. The CVs are highest in Prekharif season except Sylhet and lowest in Kharif season except Khulna. The highest average AMXT is found to be 34.8 in Rajshahi and the lowest is 33.0 in Chittagong.

\section{Between-Year Variability: Annual and Seasonal AMXT}

Table 3 presents the rates obtained from LT for annual and seasonal AMXT of the six divisions and the residual's stationarity and normality. The rate of growth of annual AMXT is found negative for Rajshahi (- 0.00863) while for others it is experienced to be positive where the significant positive growth rate is demonstrated in Dhaka $(0.0134 *)$, Barisal $\left(0.00788^{*}\right)$ and Sylhet $(0.0272 *)$. Chittagong (0.0280) ranks the highest rate with the nonstationary residual and Khulna (0.00405) ranks the lowest rate with the normal and stationary residual.

Table 2. Within-Year Variability for Annual and Seasonal AMXT

\begin{tabular}{|c|c|c|c|c|c|c|c|c|c|c|c|c|c|c|c|c|c|c|c|c|c|c|c|c|}
\hline \multirow{2}{*}{ Issues } & \multicolumn{4}{|c|}{ Dhaka } & \multicolumn{4}{|c|}{ Khulna } & \multicolumn{4}{|c|}{ Rajshahi } & \multicolumn{4}{|c|}{ Barisal } & \multicolumn{4}{|c|}{ Sylhet } & \multicolumn{4}{|c|}{ Chittagong } \\
\hline & A & $\mathbf{K}$ & PK & $\mathbf{R}$ & A & $\mathbf{K}$ & PK & $\mathbf{R}$ & A & $\mathbf{K}$ & PK & $\mathbf{R}$ & A & $\mathbf{K}$ & PK & $\mathbf{R}$ & A & $\mathbf{K}$ & PK & $\mathbf{R}$ & A & $\mathbf{K}$ & PK & $\mathbf{R}$ \\
\hline Iax & 34.9 & 35.6 & 40.3 & 32.5 & 35. & 936.2 & 41.6 & 33.0 & 36.1 & 37.3 & 43.0 & 31.5 & 34.4 & 35.3 & 38.2 & 32.0 & 34.8 & 36.6 & 38.3 & 32.1 & 34.7 & 35.93 & 38.2 & 33.0 \\
\hline ve & 33.6 & 34 & & 304 & 34.3 & & 37.4 & & 34.8 & 35.6 & & 30.2 & 33.4 & 34.2 & 35.9 . & & 33.3 & 34.8 & 35.0 & 30.0 & 33.0 & & 0 & 30.6 \\
\hline Min & 31.7 & 32.9 & 32.4 & 29.0 & 32. & 932.4 & 34.8 & 29.9 & 33.1 & 33.5 & 35.9 & 28.9 & 32.1 & 32.9 & 33.8 & 29.2 & 32.1 & 33.4 . & \begin{tabular}{|l|l|}
32.82 \\
\end{tabular} & 28.2 & 231.8 & 32.83 & 32.7 & 29.0 \\
\hline $\mathrm{CV}$ & 1.7 & 2.2 & 3.6 & 2.3 & 1.7 & 2.1 & 3.0 & 2.0 & 1.7 & 2.2 & \begin{tabular}{|l|}
3.4 \\
\end{tabular} & 2.3 & \begin{tabular}{|l|}
1.4 \\
\end{tabular} & 1.6 & 2.3 & 2.0 & 2.0 & 2.1 & 2.7 & 2.8 & 2.2 & 2.2 & 3.0 & 2.9 \\
\hline
\end{tabular}

During Kharif season, the positive growth rate is documented for all the stations where highly significant positive growth rates are established for Dhaka $(0.0366 *)$, Sylhet $(0.0359 *)$ and Chittagong $(0.0291 *)$. Barisal demontrates the significant positive rate $\left(0.0144^{*}\right)$ too but Rajshahi ranks the lowest rate $(0.00511)$.

During Prekharif season, the positive growth rates are attributed for Sylhet and Chittagong while negative for other four stations. The lower positive growth rate is found for Sylhet $(0.00405)$ with nonnormal residual and the higher positive growth rate is accredited for Chittagong (0.0241) with nonstationary residual. The fairly high negative rates are recognized for Dhaka (0.0201), Rajshahi (- 0.0286) and Barisal (- 0.00734) but Khulna $(-0.00439)$ ranks the lowest negative rate.
During Rabi season, the negative growth rates are allowed for Rajshahi (- 0.0108) and Khulna (0.00763 ) but positive for other four regions. The significant positive growth rate is amplified for Barisal $\left(0.0111^{*}\right)$, Sylhet $\left(0.0339^{*}\right)$. The fairly high positive rates are observed for Dhaka (0.00969) and Chittagong (0.0295) where the residuals follow nonstationarity for Chittagong (+ 0.0295).

For Rajshahi and Khulna, the growth rates of AMXT are experienced positive during Kharif season but negative in Prekharif and Rabi season. For Dhaka and Barisal, the rates are acknowledged positive during Kharif and Rabi season but negative for Prekharif season. The rates are approved positive in all the three seasons for Sylhet and Chittagong.

Table 3. Rates Obtained from LT for Annual and Seasonal AMXT and Residual's Stationarity and Normality

\begin{tabular}{|c|l|l|l|l|}
\hline Station & \multicolumn{1}{|c|}{ Annual $(\mathbf{o C} / \mathbf{y r})$} & \multicolumn{1}{|c|}{ Prekharif $(\mathbf{o C} / \mathbf{y r})$} & \multicolumn{1}{|c|}{ Rabi $(\mathbf{o C} / \mathbf{y r})$} \\
\hline Dhaka & $+0.0134^{*}(\mathrm{t}=2.95, \mathrm{~N}, \mathrm{~S})$ & $+0.0366^{*}(\mathrm{t}=9.51, \mathrm{Ap} . \mathrm{N}, \mathrm{S})$ & $-0.0201(\mathrm{t}=-1.85, \mathrm{~N}, \mathrm{~S})$ & $+0.00969(\mathrm{t}=1.64, \mathrm{~N}, \mathrm{~S})$ \\
\hline Rajshahi & $-0.00863(\mathrm{t}=-1.28, \mathrm{~N}, \mathrm{~S})$ & $+0.00511(\mathrm{t}=0.57, \mathrm{~N}, \mathrm{~S})$ & $-0.0286(\mathrm{t}=-1.88, \mathrm{~N}, \mathrm{~S})$ & $-0.0108(\mathrm{t}=-1.37, \mathrm{Ap} . \mathrm{N}, \mathrm{S})$ \\
\hline Khulna & $+0.00405(\mathrm{t}=0.97, \mathrm{~N}, \mathrm{~S})$ & $+0.0185(\mathrm{t}=3.72, \mathrm{NN}, \mathrm{S})$ & $-0.00439(\mathrm{t}=-0.54, \mathrm{NN}, \mathrm{S})$ & $-0.0076(\mathrm{t}=-1.70, \mathrm{Ap} . \mathrm{N}, \mathrm{S})$ \\
\hline Barisal & $+0.00788^{*}(\mathrm{t}=2.40, \mathrm{~N}, \mathrm{~S})$ & $+0.0144 *(\mathrm{t}=3.78, \mathrm{Ap} . \mathrm{N}, \mathrm{S})$ & $-0.00734(\mathrm{t}=-1.21, \mathrm{Ap} . \mathrm{N}, \mathrm{S})$ & $+0.0111^{*}(\mathrm{t}=2.55, \mathrm{~N}, \mathrm{~S})$ \\
\hline Sylhet & $+0.0272^{*}(\mathrm{t}=6.05, \mathrm{~N}, \mathrm{~S})$ & $+0.0359^{*}(\mathrm{t}=8.09, \mathrm{~N}, \mathrm{Ap} . \mathrm{S})$ & $+0.00405(\mathrm{t}=0.47, \mathrm{NN}, \mathrm{S})$ & $+0.0339^{*}(\mathrm{t}=5.80, \mathrm{~N}, \mathrm{~S})$ \\
\hline Chittagong & $+0.0280(\mathrm{t}=7.14, \mathrm{~N}, \mathrm{NS})$ & $+0.0291^{*}(\mathrm{t}=7.09, \mathrm{~N}, \mathrm{~S})$ & $+0.0241(\mathrm{t}=3.40, \mathrm{~N}, \mathrm{NS})$ & $+0.0295(\mathrm{t}=5.38, \mathrm{~N}, \mathrm{NS})$ \\
\hline
\end{tabular}

*Significant at the $5 \%$ level,

$\mathrm{S}=$ stationary, $\mathrm{NS}=$ not stationary, $\mathrm{NN}=$ not normal, Ap. $\mathrm{N}=$ approximately normal, Ap. $\mathrm{S}=$ approximately stationary . 


\section{CV of Annual and Seasonal AMXT}

Table 4 presents the rates obtained from LT for CV of annual and seasonal AMXT for the six divisions. The significant negative growth rates are permitted for the CV of annual AMXT of Dhaka (- $0.0282 *)$, Barisal $\left(-0.0153^{*}\right)$ and Sylhet $\left(-0.0196^{*}\right)$. The fairly high negative rates are accepted for Rajshahi $(-0.0218)$ and Chittagong $(-0.00875)$ but Khulna $(+0.0118)$ ranks the fairly high positive rate.

During Kharif season, the significant negative rate is ascribed for Rajshahi (- $\left.0.0726^{*}\right)$. The relatively higher negative rates are found for Dhaka $(-0.0135)$, Khulna $(-0.0126)$ and Chittagong $(-0.0113)$ where the residuals are approximately normal for Dhaka but nonnormal for Khulna and Chittagong. The comperetively lower positive rates are observed for Barisal (+ 0.00365) and Sylhet $(+0.00615)$ with nonnormal residual.

During Prekharif season, the significant negative rate is certified for Dhaka $(-0.0314 *)$. The very low negative rate is found for Khulna (-0.000135) with nonnormal residual. The relatively higher negative rates are found for Rajshahi (-0.0243) and Barisal ($0.0121)$. The less positive rates are observed for Sylhet (+ 0.00476) and Chittagong (+ 0.000485).

During Rabi season, the less negative rates are endorsed for Dhaka (- 0.000815) and Chittagong ($0.00197)$. The fairly high positive rate is sanctioned for Khulna $(+0.0191)$ but low for Rajshahi (+ 0.0177), Barisal (+ 0.00860) and Sylhet (+ 0.00485).

The rates of $\mathrm{LT}$ for $\mathrm{CV}$ of annual AMXT are authorized to be negative in all the stations except Khulna (positive). The CV of AMXT is allowed to be negative for all the three seasons for Dhaka but positive for all the three seasons for Sylhet. For Rajshahi and Khulna, it is attributed to be negative during Kharif and Prekharif seasons but positive during Rabi season. Barisal station demonstrates positive rate during Kharif and Rabi seasons but negative during Prekharif season while Chittagong station demonstrates negative rate during Kharif and Rabi seasons but positive during Prekharif season oppositely.

Table 4. Rates Obtained from LT for CV of Annual and Seasonal AMXT and Residual's Stationarity and Normality

\begin{tabular}{|c|c|c|c|c|}
\hline Station & Annual & Kharif & Prekharif & Rabi \\
\hline Dhaka & $-0.0282 *(\mathrm{t}=-2.60, \mathrm{~N}, \mathrm{~S})$, & $\begin{array}{l}-0.0135(\mathrm{t}=- \\
1.51, \text { Ap.N, S })\end{array}$ & $\begin{array}{l}-0.0314^{*}(\mathrm{t}=-2.02, \text { Ap. } \mathrm{N}, \\
\mathrm{S})\end{array}$ & $-0.000815(\mathrm{t}=-0.05, \mathrm{~N}, \mathrm{~S})$ \\
\hline Rajshahi & $-0.0218(\mathrm{t}=$ & $\begin{array}{l}-0.0726 *(\mathrm{t}=-2.41, \\
\text { Ap.N,S) }\end{array}$ & $\begin{array}{l}-0.0243(\mathrm{t}=-0.89, A p . N, \\
\mathrm{S})\end{array}$ & $\begin{array}{l}+0.0177(\mathrm{t}=0.77, \mathrm{~N}, \\
\text { Ap.S) }\end{array}$ \\
\hline Khulna & $+0.0118(\mathrm{t}=1.32, \mathrm{~N}, \mathrm{~S})$ & $\begin{array}{l}-0.0126(\mathrm{t}=- \\
1.18, \mathrm{NN}, \mathrm{S})\end{array}$ & $\begin{array}{l}-0.000135(\mathrm{t}=-0.01, \mathrm{NN}, \\
\mathrm{S})\end{array}$ & $+0.0191(\mathrm{t}=1.35, \mathrm{~N}, \mathrm{~S})$ \\
\hline Barisal & $\begin{array}{l}-0.0153^{*}(\mathrm{t}=-2.06, A p . \mathrm{N} \\
\text { Ap.S) }\end{array}$ & $\begin{array}{l}+0.00365(\mathrm{t}=0.40, \mathrm{NN}, \\
\mathrm{S})\end{array}$ & -0.0121 & $\begin{array}{l}+0.00860(\mathrm{t}=0.57, \mathrm{Ap} . \mathrm{N} \\
\mathrm{S})\end{array}$ \\
\hline Sylhet & $-0.0196^{*}(\mathrm{t}=-2.41, \mathrm{~N}, \mathrm{~S})$ & $\begin{array}{l}+0.00615(\mathrm{t}=0.64, \mathrm{NN}, \\
\mathrm{S})\end{array}$ & $+0.00476(\mathrm{t}=0.34, \mathrm{~N}, \mathrm{~S})$ & $\begin{array}{l}+0.00485(\mathrm{t}=0.31, \mathrm{Ap} . \mathrm{N} \\
\mathrm{S})\end{array}$ \\
\hline hittagong & $0.00875(\mathrm{t}=-1.04, \mathrm{~N}, \mathrm{~S})$ & $\begin{array}{l}-0.0113(\mathrm{t}=-1.18, \mathrm{NN}, \\
\mathrm{S})\end{array}$ & $+0.000485(\mathrm{t}=0.04, \mathrm{~N}, \mathrm{~S})$ & $-0.00197(\mathrm{t}=-0.16, \mathrm{~N}, \mathrm{~S})$ \\
\hline
\end{tabular}

\section{Model Fitting and Forecasting}

As a next step, attempt is made to fit univariate BoxJenkin's ARIMA models to forecast the monthly AMXT data for January 2009 to December 2012 in Table 5. The ACF displays for residual autocorrelations for the estimated models are fairly small relative to their standard errors for all the variables. The histograms of the residuals are symmetrical suggesting that the shocks may be normally or approximately normally distributed. The normal probability plots of the residuals do not deviate badly from straight lines (fairly close to the straight line), again suggesting that the shocks are normal. The point and interval forecasted AMXT are presented in the Table 6. Some residual plots and TS plots for Point and interval forecasts are shown in the Fig. 2. 
a
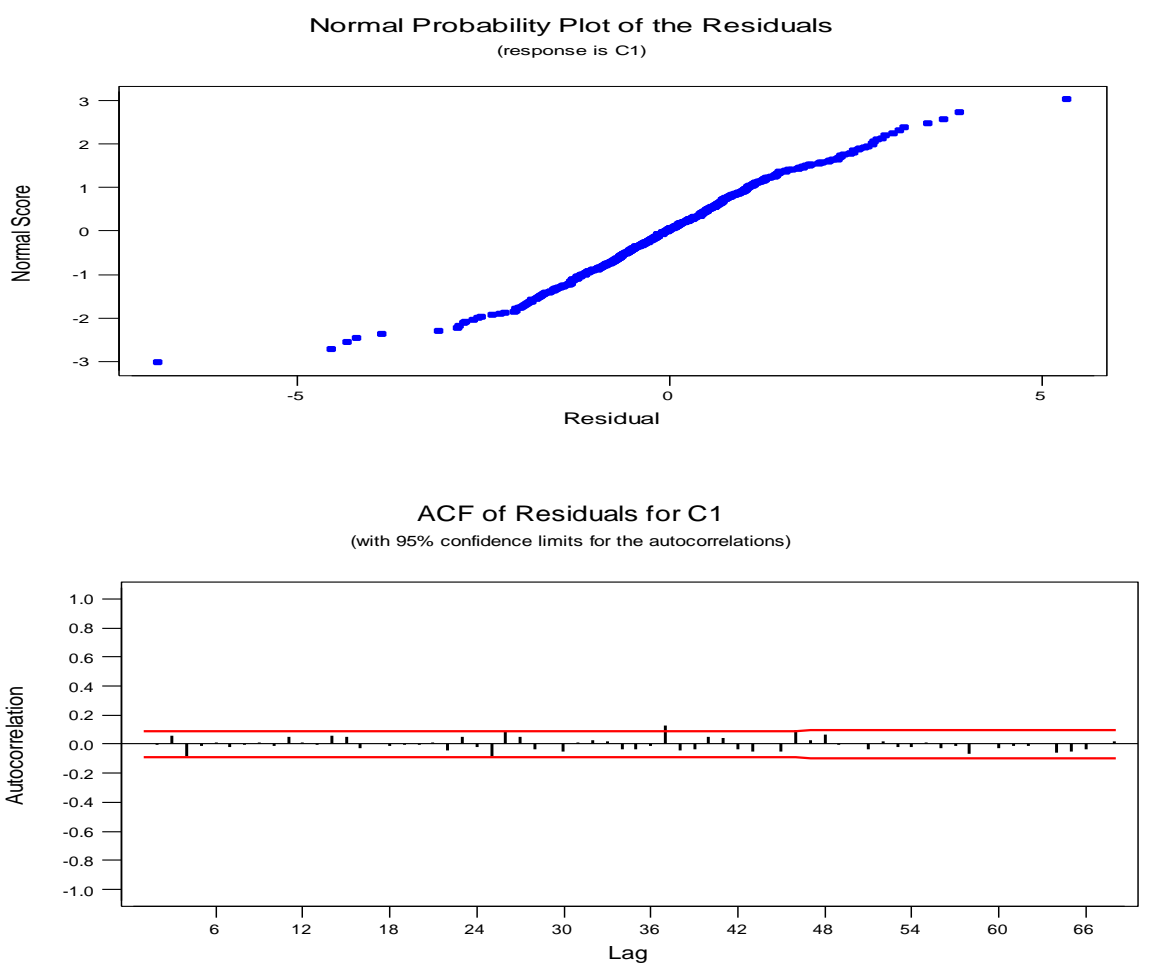

$\mathrm{c}$

Time Series Plot for C1

$\mathrm{b}$

(win forecasts and their $95 \%$ confidence limits)

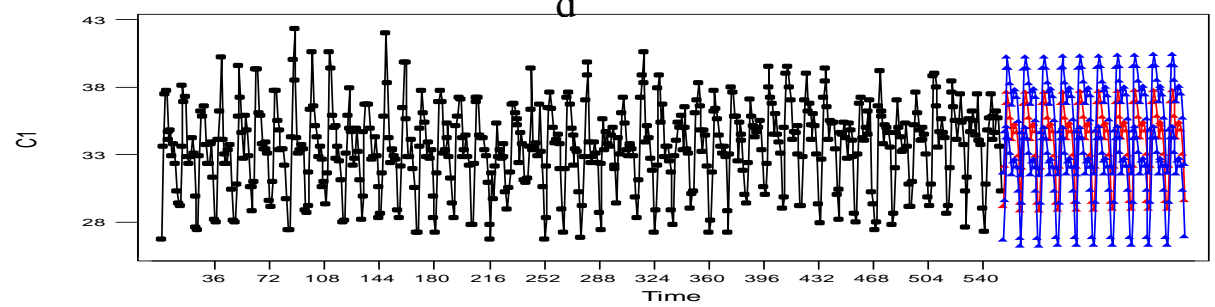

Time Series Plot for $\mathrm{C} 4$

(with forecasts and their 95\% confidence limits)

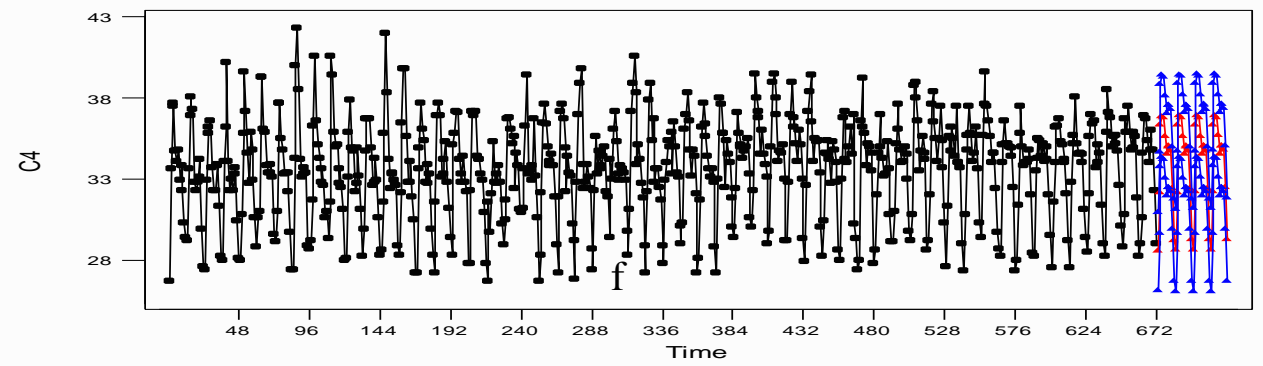

Fig. 2. (a) NP plot for residuals of Dhaka (b) ACF of residuals for Dhaka (c) Forecasted AMXT (Red line - Indication of point estimate and blue line - Indication of 95\% confidence interval) for Dhaka (d) Forecasted AMXT for 2009-2012 for Dhaka 
Table 5. ARIMA Models for Monthly AMXT for Six Stations

\begin{tabular}{|c|c|c|c|c|c|c|}
\hline Variable & Model & Equation of Model & MRMSFE & SS & DF & MS \\
\hline Dhaka & $\begin{array}{c}\text { ARIMA } \\
(1,0,1)(0,1,1)_{12}\end{array}$ & $(1-0.5078 \mathrm{~B}) \nabla_{12} \mathrm{y}_{\mathrm{t}}=0.006193+(1-0.2193 \mathrm{~B})\left(1-0.9148 \mathrm{~B}^{12}\right.$ & 1.223 & 990.10 & 656 & 1.509 \\
\hline Khulna & $\begin{array}{c}\text { ARIMA } \\
(1,1,1)(0,1,1)_{12} \\
\end{array}$ & $\begin{array}{c}(1-0.1781 \mathrm{~B}) \nabla \nabla_{12} \mathrm{y}_{\mathrm{t}}=-0.000095+(1-0.9402 \mathrm{~B})\left(1-0.956 \mathrm{~B}^{12}\right. \\
) \varepsilon_{\mathrm{t}}\end{array}$ & 1.158 & 1048.58 & 715 & 1.47 \\
\hline Rajshahi & $\begin{array}{c}\text { ARIMA } \\
(1,0,1)(1,1,1)_{12}\end{array}$ & $\begin{array}{c}(1-0.5422 \mathrm{~B})\left(1+0.0237 \mathrm{~B}^{12}\right) \nabla_{12} \mathrm{y}_{\mathrm{t}}=-0.00396+(1-0.3349 \mathrm{~B}) \\
\left(1-0.9626 \mathrm{~B}^{12}\right) \varepsilon_{\mathrm{t}} \\
\text { se of coeff. }(0.1431)(0.0443)(0.002726)(0.1613)(0.0191)\end{array}$ & 1.386 & 1107.00 & 523 & 2.12 \\
\hline $\begin{array}{c}\text { Barisa } \\
1 \\
\end{array}$ & $\begin{array}{l}\text { SQRT T } \\
\text { ARIMA } \\
(101)(011) \\
\end{array}$ & 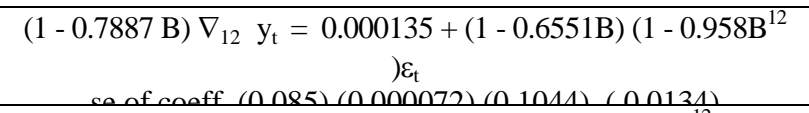 & 0.078 & 6.04 & 704 & 0.008 \\
\hline Sylhet & ARIMA & $\begin{array}{l}\nabla \nabla_{12} \mathrm{y}_{\mathrm{t}}=0.000103+(1-0.9565 \mathrm{~B})\left(1-0.9624 \mathrm{~B}^{12}\right) \varepsilon_{\mathrm{t}} \\
\text { se of coeff. }(0.000194)(0.0117)(0.0143)\end{array}$ & 1.153 & 828.55 & 620 & $\begin{array}{c}1.33 \\
6\end{array}$ \\
\hline $\begin{array}{l}\text { Chitta- } \\
\text { gong }\end{array}$ & $\begin{array}{c}\text { ARIMA } \\
(1,0,1)(1,1,1) \\
12\end{array}$ & $\begin{array}{c}\quad(1-0.9973 \mathrm{~B})\left(1-0.017 \mathrm{~B}^{12}\right) \nabla_{12} \mathrm{y}_{\mathrm{t}}=0.000222+(1- \\
0.9609 \mathrm{~B})\left(1-0.9652 \mathrm{~B}^{12}\right) \varepsilon_{\mathrm{t}} \\
\text { se of coeff. }(0.0056)(0.039)(0.000604)(0.0002)(0.0153)\end{array}$ & 1.555 & 867.13 & 703 & $\begin{array}{c}1.23 \\
3\end{array}$ \\
\hline
\end{tabular}

*SQRT T= Square root transformed, MRMSFE= Minimum root mean square forecasting error,

MS = Mean square error, $\quad$ se of coeff. $=$ Standard error of coefficient

Table 6. Point and Interval Forecasts of Monthly AMXT

\begin{tabular}{|c|c|c|c|c|c|c|c|c|c|c|c|c|c|c|c|c|c|c|}
\hline \multirow[t]{2}{*}{ Period } & \multicolumn{3}{|c|}{ Dhaka for 2009} & \multicolumn{3}{|c|}{ Khulna for 2009} & \multicolumn{3}{|c|}{ Rajshahi for 2009} & \multicolumn{3}{|c|}{ Barisal for 2009} & \multicolumn{3}{|c|}{ Sylhet for 2009} & \multicolumn{3}{|c|}{$\begin{array}{c}\text { Chittagong for } \\
2009\end{array}$} \\
\hline & $\mathbf{P}$ & $F(\mathrm{~L})$ & 1 & PE & $\mathbf{E}(\mathbf{L})$ & 1 & $\mathbf{P E}$ & Fo & $F(\mathbf{I}$ & PE & IE(L) & IE(I & PE & $\mathbf{F o}$ & Fol & ST & & TNon \\
\hline & 285 & & 300 & 9.2 & 26.8 & 31.5 & 27.9 & 250 & 307 & 29.2 & 7 & 31.2 & 9.3 & 27.1 & & $\overline{0.6}$ & 28.4 & \\
\hline & & & & & & & & & & 32.3 & & & 9 & & & 2.8 & & \\
\hline & & & & & & & & & & & & & & & & & & \\
\hline & & & & & & & & & & & & & & & & & & \\
\hline & & & & & & & & & & & & 8.3 & 4 & & 7 & 5.5 & & 38.7 \\
\hline & & & & & & & & & & & & & & & & & & \\
\hline & & & & & & & & & & & & .1 & & & 5 & & & 7 \\
\hline & & & & & & & & & & & & 6.5 & & & 5 & & & 37. \\
\hline & & & & & & & 36 & & & 34 & & $\pi$ & 0 & & ( & 6 & & 37 \\
\hline & & & & & & & & & & & & & & & & & & \\
\hline & & & & & & & & & & & & 3 & $\overline{0}$ & & 35.3 & 34.1 & & \\
\hline cembe & 29.2 & 26.7 & 31.8 & 29.2 & 26. & 31.7 & 28.2 & 25. & 31.2 & 29.5 & 27 & 31.5 & 30.0 & 27 & 32.3 & 31.2 & 29.0 & 33.4 \\
\hline
\end{tabular}

$\mathrm{PE}=$ point estimate $\mathrm{IE}(\mathrm{L})=$ interval estimate (lower bound) $\mathrm{IE}(\mathrm{U})=$ interval estimate (upper bound)

Table 6. continued

\begin{tabular}{|c|c|c|c|c|c|c|c|c|c|c|c|c|c|c|c|c|c|c|}
\hline \multirow[t]{2}{*}{ Period } & \multicolumn{3}{|c|}{ Dhaka for 2010} & \multicolumn{3}{|c|}{ Khulna for 2010} & \multicolumn{3}{|c|}{ Rajshahi for 2010} & \multicolumn{3}{|c|}{ Barisal for 2010} & \multicolumn{3}{|c|}{ Sylhet for 2010} & \multicolumn{3}{|c|}{$\begin{array}{c}\text { Chittagong for } \\
2010 \\
\end{array}$} \\
\hline & PE & IE $(\mathbf{L})$ & & $\mathbf{P E}$ & & & & & & & & & PE & & & PE & IE(L) & $\mathbf{I E}(\mathbf{U})$ \\
\hline & & & & & & & & & & & & & & & & .7 & & \\
\hline & & & & & & & & & & & & & & & & .9 & & \\
\hline & & & & & & & & & & & & & & & & & & \\
\hline & & & & & & & & & & & & & & & & & & \\
\hline & & & & & & & & & & & & & & & & & & \\
\hline & & & & & & & & & & & & & 5.2 & & & 5.9 & & \\
\hline & & & & & & & & & & & & & & & & .2 & & \\
\hline & & & & & & & & & & & & & & & & & & \\
\hline & & & & & & & & & & & & & & & & 5.6 & & \\
\hline & & & & 34 & & \begin{tabular}{|l|}
37.1 \\
\end{tabular} & & & \begin{tabular}{|l|}
37.1 \\
\end{tabular} & 34. & & & 35.3 & 1 & 7.6 & 35.6 & 4 & 7.9 \\
\hline & & & & & & & & & & & & & & & & 84 & & \\
\hline & 2 & & & 29 & 26. & & & & & 29 & & & 30 & & 32.4 & 31.3 & & \\
\hline
\end{tabular}


Table 6. continued

\begin{tabular}{|c|c|c|c|c|c|c|c|c|c|c|c|c|c|c|c|c|c|c|}
\hline \multirow{2}{*}{ Period } & \multicolumn{3}{|c|}{ Dhaka for 2011} & \multicolumn{3}{|c|}{ Khulna for 2011} & \multicolumn{3}{|c|}{ Rajshahi for 2011} & \multicolumn{3}{|c|}{ Barisal for 2011} & \multicolumn{3}{|c|}{ Sylhet for 2011} & \multicolumn{3}{|c|}{ Chittagong for 2011} \\
\hline & PE & JF(I) & IE(I) & DF & & IE(U) & & & $\mathrm{IE}(\mathbf{U})$ & $\mathbf{P E}$ & & IE(U) & $\mathbf{P E}$ & IE(L) & IE(U) & $\mathbf{P E}$ & IE(L) & IE(U) \\
\hline & & & & & & & & & & & & & & & & & & \\
\hline & & & & & & & & & & & & & & & & & & .2 \\
\hline & & & & & & & & & & & & & & & & & & 37.9 \\
\hline & & & & & & & & & & & & & & & & & & 3.6 \\
\hline & & & & & & & & & & & & & & & & & & 9 \\
\hline & & & & & & & & & & & & & 5.2 & & & & & 38.2 \\
\hline & & & & & & & & & & & & & 4 & & & & & 37.5 \\
\hline & & & & & & & & & & & & & 5.4 & & .7 & & & 37.6 \\
\hline & & & & & & & & & & & & & 36.1 & & .5 & & & 38.0 \\
\hline & & & & & & & & & & & & & & & 7.7 & & & 38.0 \\
\hline & & & & & & & & & & & & & 33.1 & & & & & 36.5 \\
\hline ecember & 29.2 & 20.1 & 31.8 & 29.2 & 26.5 & 31.8 & 28.2 & 25.3 & 31.2 & 29.5 & 27.5 & 31.5 & 30.1 & 27.8 & 32.5 & 31.3 & 29.1 & 33.6 \\
\hline
\end{tabular}

Table 6. continued

\begin{tabular}{|c|c|c|c|c|c|c|c|c|c|c|c|c|c|c|c|c|c|c|}
\hline \multirow{2}{*}{ Period } & \multicolumn{3}{|c|}{ Dhaka for 2012} & \multicolumn{3}{|c|}{ Khulna for 2012} & \multicolumn{3}{|c|}{ Rajshahi for 2012} & \multicolumn{3}{|c|}{ Barisal for 2012} & \multicolumn{3}{|c|}{ Sylhet for 2012} & \multicolumn{3}{|c|}{ Chittagong for 2012 } \\
\hline & $\mathbf{P E}$ & $\mathrm{IE}(\mathbf{L})$ & IFE & PE & $\mathrm{IE}(\mathbf{L})$ & IE(U) & PE & IE(L) & $\mathrm{IE}(\mathbf{U})$ & $\mathbf{P E}$ & IE(L) & IE(U) & $\mathbf{P E}$ & IE(L) & $\mathrm{IE}(\mathbf{U})$ & $\mathbf{P E}$ & IF & \\
\hline 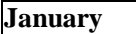 & 86 & & & 0 & & 17 & & & & & & & & & & & & \\
\hline & & & & & & & & & & & & & & & & & & 3 \\
\hline & & & & & & & & & & & & & & & & & & 0 \\
\hline & & & & & & & & & & & & & .2 & & & & & 8.7 \\
\hline & & & & & & & & & & & & & 6 & & & & & 99.0 \\
\hline & & & & & & & 8.1 & & & & 3 & 37. & 36.3 & & .7 & .1 & & 88.3 \\
\hline & 6 & & & 4.5 & & & 4.9 & & & 9 & 7 & - & 36.4 & & 38.8 & .3 & & 37.6 \\
\hline & & & & 34.4 & & & 3 & & & 34.3 & .1 & 36. & 36.4 & & 8.8 & 5.4 & & 37.7 \\
\hline & & & & 34.9 & & & 8 & & & 34.6 & .5 & 36. & 36.2 & .8 & 38.6 & 5.8 & & 38.0 \\
\hline & & & & 34.4 & & & 34. & & & 34.4 & & 36 & 35.4 & & 37.8 & 5.8 & & 38.0 \\
\hline & & & & 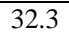 & 29 & & 21 & & & 32 & & 34 & 33.2 & 2 & 35. & 34.3 & .0 & 36.6 \\
\hline ecember & 9.3 & 26.7 & 31.8 & 29.1 & 26.3 & 31.9 & 28.2 & 25.3 & 31.1 & 29.5 & 27.5 & 31.5 & 30.2 & 27.8 & 32.6 & 31.4 & 29.1 & 33.7 \\
\hline
\end{tabular}

\section{Conclusions}

The maximum, average and minimum AMXT are highest in Prekharif season and lowest in Rabi season for all the six studied stations. The CV is highest in Prekharif season except Sylhet and lowest in Kharif season except Khulna. The highest average AMXT is found to be 34.8 in Rajshahi and the lowest to be 33.0 in Chittagong.

The growth rates of annual AMXT are found to be positive in all the six stations analyzed except Rajshahi which is negative. The growth rates of $\mathrm{CV}$ of annual AMXT are established to be negative in all the six stations except Khulna which is positive. The rates of AMXT are documented to be positive during Kharif season but negative in Prekharif and Rabi seasons for Rajshahi and Khulna. The rates are attributed to be positive during Kharif and Rabi seasons but negative in Prekharif season for Dhaka and Barisal. The rates are found to be positive in all the three seasons for Sylhet and Chittagong.

The well fitted ARIMA model for the monthly AMXT of Dhaka, Khulna, Rajshahi, Barisal, Sylhet and Chittagong are $\operatorname{ARIMA}(1,0,1)(0,1,1)_{12}, \quad \operatorname{ARIMA}(1,1,1)(0,1,1)_{12}$ ARIMA $(1,0,1)(1,1,1)_{12}, \quad$ SQRT T ARIMA $(1,0,1)(0,1,1)_{12}$ $\operatorname{ARIMA}(0,1,1)(0,1,1)_{12} \quad \operatorname{ARIMA}(1,0,1)(1,1,1)_{12}$, respectively on the basis of minimum root mean square forecasting error for the last ten years of the 120 observations.
The findings pinpoints that the climate of this country is changing in terms of maximum temperature and this may have adverse impacts on its crop production. Hence, judicious planning is very much essential to suit with the changes for sustainable development of its agriculture.

\section{References}

Box, G. E. P. and Jenkins, G. M. 1976. Time Series Analysis: Forecasting and Control, Prentince Hall, Inc.575p.

Gujarati, D. N. 1995. Basic Econometrics, 3rd ed. McGraw-Hill, New York.

Hamilton, J. D. 1994. Time Series Analysis, Princeton University Press, Princeton NJ.

Hendry, D. F and Juselius, K. 2001. Explaining Cointegration Analysis: Part I. Energy Journal 21: 142

Hendry, D. F and Juselius, K. 2003. Explaining Cointegration Analysis: Part II. Energy Journal 22: 75120

Lenka, D. 1998. Climate, Weather and Crops in India. New Delhi, India.

Pankraiz, A. 1991. Forecasting with Dynamic Regression Models. John Wiley and Sons Inc. New York.

Stain, M. and Lloret, J. 2001. Forecasting of Air and Water Temperatures for fishery purposes with Selected Examples from Northwest Atlantic. J. Northw. Atl. Fish. Sci., 29: 23-30 


\section{Appendix 1: Standardized ARIMA Notation}

ARIMA models have a general form of $(\mathrm{p}, \mathrm{d}, \mathrm{q})$ where $\mathrm{p}$ is the order of standard autoregressive term AR, $\mathrm{q}$ is the order of the standard moving average term MA and $d$ is the order of differencing AR describes how a variable $y_{t}$ such as maximum temperatures depends on some previous values $\mathrm{y}_{\mathrm{t}-1}, \mathrm{y}_{\mathrm{t}-2}$ etc. while MA describes how this variable $\mathrm{y}_{\mathrm{t}}$ depends on a weighted

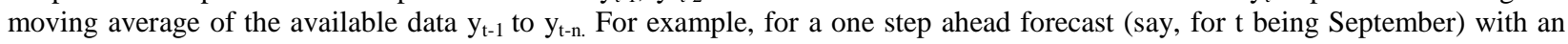
AR-1, all weight is given to the maximum temperatures in the previous month (September), while with an AR-2 the weight is given to the maximum temperatures of the two immediately previous months (September and August). By contrast, with a MA-1, MA-2, a certain weight is given to the maximum temperature of the immediately previous month (September), a smaller weight is given to the maximum temperature observed two months ago (August) and so forth, i.e., the weights decline exponentially.

The combined multiplicative seasonal ARIMA (p, d, q) $\times 12(\mathrm{P}, \mathrm{D}, \mathrm{Q})$ model gives the following:

$\phi_{p}(B) \Phi_{p}\left(B^{s}\right) \nabla_{s}^{D} \nabla^{d} z_{t}=C+\theta_{q}(B) \Theta_{Q}\left(B^{s}\right) \varepsilon_{t}$

The standard expression of ARIMA model where B denotes the backward shift operator where

- $\phi_{p}(B)=1-\phi_{1} B-\phi_{2} B^{2}-\ldots-\phi_{p} B^{p}$

The standard autoregressive operator of order $\mathrm{p}$

- $\Phi_{p}\left(B^{s}\right)=1-\Phi_{1} B-\Phi_{2} B^{2}-\ldots-\Phi_{p} B^{p s}$

The seasonal autoregressive operator of order $\mathrm{p}$

$-\nabla_{s}^{D}$ is the seasonal differencing operator of order $\mathrm{D}$

$-\nabla^{d}$ is the differencing operator of order $\mathrm{d}$

$-\mathrm{y}_{\mathrm{t}}$ is the value of the variable of interest at time $\mathrm{t}$

- $C=\mu \phi_{p}(B) \Phi_{p}\left(B^{s}\right)$ is a constant term, where $\mu$ is the true mean of the stationary time series being modeled. It was estimated from sample data using the approximate likelihood estimator approach.

$-\theta_{q}(B)=1-\theta_{1} B-\theta_{2} B^{2}-\ldots-\theta_{q} B^{q}$

The standard moving average operator of order $\mathrm{q}$

$-\Theta_{Q}\left(B^{s}\right)=1-\Theta_{1} B^{1}-\Theta_{2} B^{2}-\ldots-\Theta_{Q} B^{Q S}$

The seasonal moving average operator of order $\mathrm{Q}$

- $\phi_{1}, \phi_{2}, \ldots . ., \phi_{p} ; \Phi_{1}, \Phi_{2}, \ldots, \Phi_{p} ; \theta_{1}, \theta_{2}, \ldots, \theta_{q} ; \Theta_{1} \Theta_{2}, \ldots, \Theta_{Q}$ are unknown coefficients that are estimated from sample data using the approximate likelihood estimator approach.

$-\varepsilon_{\mathrm{t}}$ is the error term at time at time $\mathrm{t}$

-S is the annual period, i,e. 12 months

Thus, the multiplicative seasonal modeling approach which has a general form of ARIMA (p, d, q) $\times S(P, D, Q)$ has been used in this paper. In this form, $\mathrm{p}$ is order of the seasonal autoregressive term (ARS), $\mathrm{Q}$ is order of the seasonal moving average term, D is the order of the seasonal differencing and $\mathrm{s}$ is the annual cycle (e.g, $\mathrm{s}=12$ using the monthly data). ARS describes how variable $\mathrm{y}$ depends on $\mathrm{y}_{\mathrm{t}-12}$ (ARS-1), $\mathrm{y}_{\mathrm{t}-24}$ (ARS-2), etc., while MAS describes how y depends on a weighted moving average of the available data $\mathrm{y}_{\mathrm{t}-12}$ to $\mathrm{y}_{\mathrm{t}-12 \mathrm{n}}$. For example, for a one step ahead forecast (say, for $\mathrm{t}$ being September and with an ARS-1, all weight is given to the maximum temperatures in the previous September while with an ARS-2, the weight is given to the September maximum temperatures 1 and 2 years ago. By contrast, with a MAS-1, MAS-2, the model gives a certain weight to September maximum temperature 1 year ago, to the September maximum temperatures 2 years ago, and so on. These weights decline exponentially. 